\title{
A PROBABILISTIC ANALISYS OF THE FORCES IN THE PILES OF A CONTAINER TERMINAL WHARF UNDER SHIP BERTHING ACTIONS
}

\author{
André Pereira Ramos ${ }^{1}$, João Paulo Silva Lima ${ }^{1}$ \& Mauro de Vasconcellos Real ${ }^{I^{*}}$
}

\begin{abstract}
RAMOS, A.P.; LIMA, J.P.S.; REAL, M.V. A probabilistic analisys of the forces in the piles of a container terminal wharf under ship berthing actions. Perspectivas Online: Exatas \& Engenharias, v. 8, n.20, p.78-88,2018.

In this work a probabilistic structural analysis of a container terminal wharf is presented. Through the application of the Monte Carlo Simulations in a finite element structural model, the statistics of the axial forces at the pile heads were evaluated. Considering only ship berthing conditions, but varying equipment type, number and positions, ten external load combinations were analyzed and compared. Both finite element model and probabilistic analysis were performed in ANSYS software, v.16, on its APDL Mechanical and Probabilistic Design System packages respectively. The random input parameters considered were the concrete structure, pavement and rear landfill self-weight, live loads and ship sizes, for which statistical parameters were

collection. PIANC's berthing energy method for fender systems design was applied for the evaluation of ship berthing forces acting on the structure. Considering the axial forces as the main parameters in the design of partially embedded piles, the random output parameters obtained were the minimum and maximum axial forces on each simulation. That approach, applied due to the possibility of ANSYS to be programmed through its Parametric Design Language (APDL), proved to be a powerful tool for probabilistic analysis of complex structural systems. The results present a comparison between the statistical parameters and probability density curves for the ten cases analyzed, by which the worst combinations from a probabilistic point of view could be defined.
\end{abstract} attributed based on bibliography or data

Keywords: Container terminal berth; Probabilistic Analisys; Monte Carlo Method; Finite Element Method; ANSYS.

\footnotetext{
${ }^{1}$ Universidade Federal do Rio Grande, FURG - Rua Visc. De Paranaguá, 102, Centro, Rio Grande, RS, CEP: $96203-$ 900, Brasil;

(*)e-mail: mauroreal@furg.br

Data de chegada: 07/05/2017 Aceito para publicação: 29/05/2017
}

Persp. Online: exatas \& eng., Campos dos Goytacazes, 20 (08) 78-88 - 2018 


\section{INTRODUCTION}

Since they integrate most of supply chains existing nowadays, port structures play a fundamental role in our society. Thus, to guarantee that these structures will perform within the required safety and functionality conditions must be the main objective of structural design. A rational criteria for ensuring that a structure will work within those conditions is given in terms of structural reliability, that can be defined as the probability of a structural system to fulfill its design purpose, or, in other words, the probability that a structure will not fail when performing its intended function. A traditional idea of safety in structural engineering problems is associated with the ultimate limit states, defined as the boundaries between desired and undesired structural performances. Limit state functions can be described as the difference between resistance and load effects, and represent failure when assume values less than zero. The probability of failure of a structure is the probability of violating any of those limit states, or the probability of load effects to overcome the resistance. It is well known that uncertainties in engineering are unavoidable, causing many parameters used in the design of the structures, generally taken as deterministic, to be associated to some kind of randomness. Because of those uncertainties, loads and resistances of structures are, actually, random variables that may be described by their statistical parameters (NOWAK e COLLINS, 2000).

In order to obtain subsidies for subsequent reliability analyses, the objective of the present work is to determine the statistical parameters of the axial forces acting at the pile heads of a berthing port structure. A case study of an existing wharf is presented, and a number of ten possible load combinations were analyzed.

The structure was modeled using the Finite Element Method through ANSYS software, on its APDL Mechanical interface, and the Monte Carlo Simulations were performed in ANSYS Probabilistic Design System. Several input random parameters were determined based on both bibliography and data collection sources. From the assumption that the axial internal forces play the main role in the design of partially embedded piles, the output random parameters obtained were the internal minimum and maximum axial forces on each simulation. As the software does not have a specific function for the required output parameters, a subroutine for finding those values at each simulation had to be implemented through ANSYS Parametric Design Language (APDL).

\section{METHODOLOGY}

\subsection{Random variables and the Gaussian probability distribution}

Random variables are mathematical vehicles for describing events in analytical forms (ANG e TANG, 2007). Contrasting to deterministic variables that are assumed by a determined value, random variables are defined within a range of possible values. As they represent events, the numerical values of the random variables are associated with specific probability or probability measures, what may be assigned in accordance to prescribed rules called probability distributions, and there are many of those distributions suitable to various behaviors of random variables.

Due to its wide range of applicability, the best known and most used probability function is the normal or Gaussian distribution. For a continuous random variable , the normal probability density function (PDF) is given by

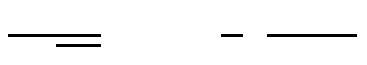

where and are the mean and the standard deviation of the random variable , respectively.

In the present work all the input and output parameters were treated as normal distributed random variables, having their behaviors following Eq. (1).

Persp. Online: exatas \& eng., Campos dos Goytacazes, 20 (08) 78-88 - 2018

seer.perspectivasonline.com.br 


\subsection{The analysed structural system}

The structure analyzed in this work integrates the Rio Grande City Harbor Container Terminal (TECON), located at the entrance of the port region. It consists of a $900 \mathrm{~m}$ long and $20 \mathrm{~m}$ wide open wharf, structurally divided into 18 modules of $50 \mathrm{~m}$, equipped each one with two 100 ton steel bollards and two flexible fenders. Each module has 60 concrete piles, with tubular cross sections, of which 24 are inclined. The superstructure consists in a horizontal frame of longitudinal and transversal beams which supports a 0.2 $\mathrm{m}$ thickness slab, all in reinforced concrete. In a total of five, the longitudinal beams run throughout the extension of each module, having different cross-sections and made in both cast-in-place and precast concrete. With the exception of two cast-in-place beams located at the edges of each module, all the 86 transversal beams are built in precast concrete with pi type cross-section. The concrete slab is covered by a $0.50 \mathrm{~m}$ pavement surface composed of $0.40 \mathrm{~m}$ sand and $0.10 \mathrm{~m}$ interlocked concrete blocks layers. The general arrangement of the structure is presented in Fig. 1, and the ANSYS built computational model is presented in Fig. 2.

Despite having a slab composing its superstructure, the wharf was modeled only with linear elements. As the slab is solidarized to the beams frame, its stiffness in each direction was numerically added to the beams. The structural analysis was performed in ANSYS APDL Mechanical package, on its version v.16. All structural parts were modeled with the element Beam189, suitable for analyzing slender to moderately stubby/thick beam structures (ANSYS, 2016).

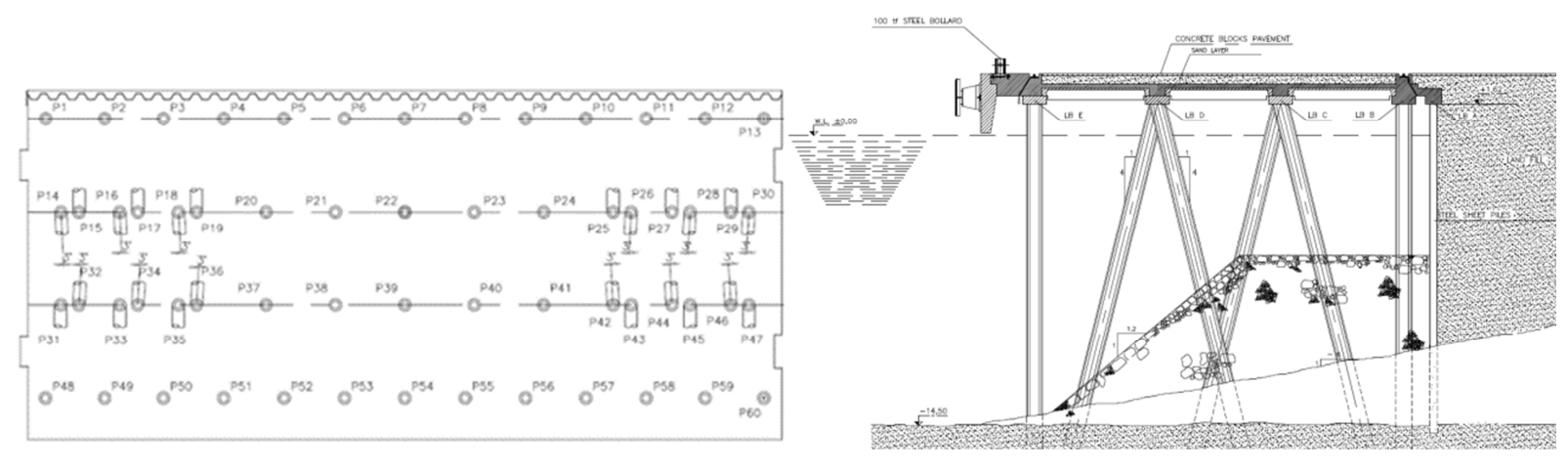

Figure 1: Top and cross section design drawings of the TECON's wharf (Source: TECON).

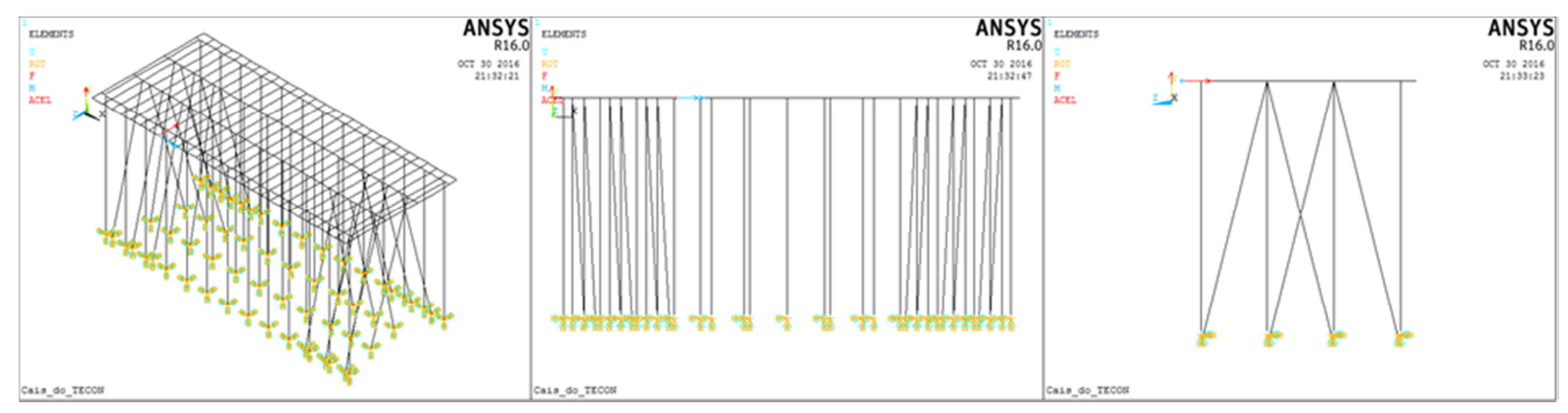

Figure 2: TECON's wharf structural model in perspective, front and lateral views.

\subsection{Structural actions and load combinations}

An interesting classification for the actions on berth structures is presented by Thoresen (2014). By the author, there are three main categories of actions on those structures: loads from the sea side, on the structure itself and from the land side.

In the present analysis, the only action from the sea side was the ship berthing impact, given by a horizontal force acting against the structure at the fender location point. For the evaluation of its intensity

Persp. Online: exatas \& eng., Campos dos Goytacazes, 20 (08) 78-88 - 2018

seer.perspectivasonline.com.br 
PIANC's berthing energy method was applied. According to that, the energy that must be absorbed by a fender as a ship berths is

where:

$$
\begin{aligned}
& =\text { energy to be absorbed by the fendem system }(\mathrm{kNm}) \\
& =\text { mass of the vessel (displacement in tonnes); } \\
& =\text { approach velocity of the vessel }(\mathrm{m} / \mathrm{s}) \\
& =\text { eccentricity factor; } \\
& =\text { virtual mass factor; } \\
& =\text { softness factor; } \\
& =\text { berthing configuration factor. }
\end{aligned}
$$

According to the British Standard BS 6349-I, the displacement of a container vessel can be estimated multiplying by 1.4 the vessel deadweight, which represents the total mass of cargo, stores, fuels, crew and reserves with which a vessel is laden when submerged to the summer loading line. For the approach velocity, the Brolsma's curve for easy berthing under exposed conditions was used. After evaluating the berthing energy, the force acting in the structure is obtained dividing the berthing energy by the $\mathrm{E} / \mathrm{R}$ fender parameter (Energy/Reaction), which is specific for the different types of fender and provided by the manufacturers. The complete formulation and factor values for several ship and berths conditions are found in PIANC (2002).

Actions on the structure itself were the concrete, pavement layer and equipment self-weights, live loads and thermal forces due to temperature variations. Concrete self-weight and temperature were introduced in the computational model as body loads, while pavement layer and live loads were input as distributed vertical forces on the beams where such actions occur. Concerning to the equipment self-weight, ship-to-shore (STS) cranes actions were input as vertical distributed forces on the two longitudinal beams located on the vertical piles lines, and mobile harbour cranes (MHC) actions were input as concentrated vertical forces acting on predefined transversal beams.

The only load from the land side introduced was the sheet pile horizontal reaction on the rear beam, input as a horizontal distributed force. Actions such contact forces from adjacent modules and winds, waves and currents effects on the structure were not considered in this work.

\subsubsection{Statistics of the structural actions}

To perform a probabilistic analysis in a structural model the statistics of its random input parameters must be known. As all input random variables were considered as having normal distributions, their behaviors are completely described by mean $\mu$ and standard deviation $\sigma$ values. The input random variables statistics and probability density curves are presented in the Fig. 3. 

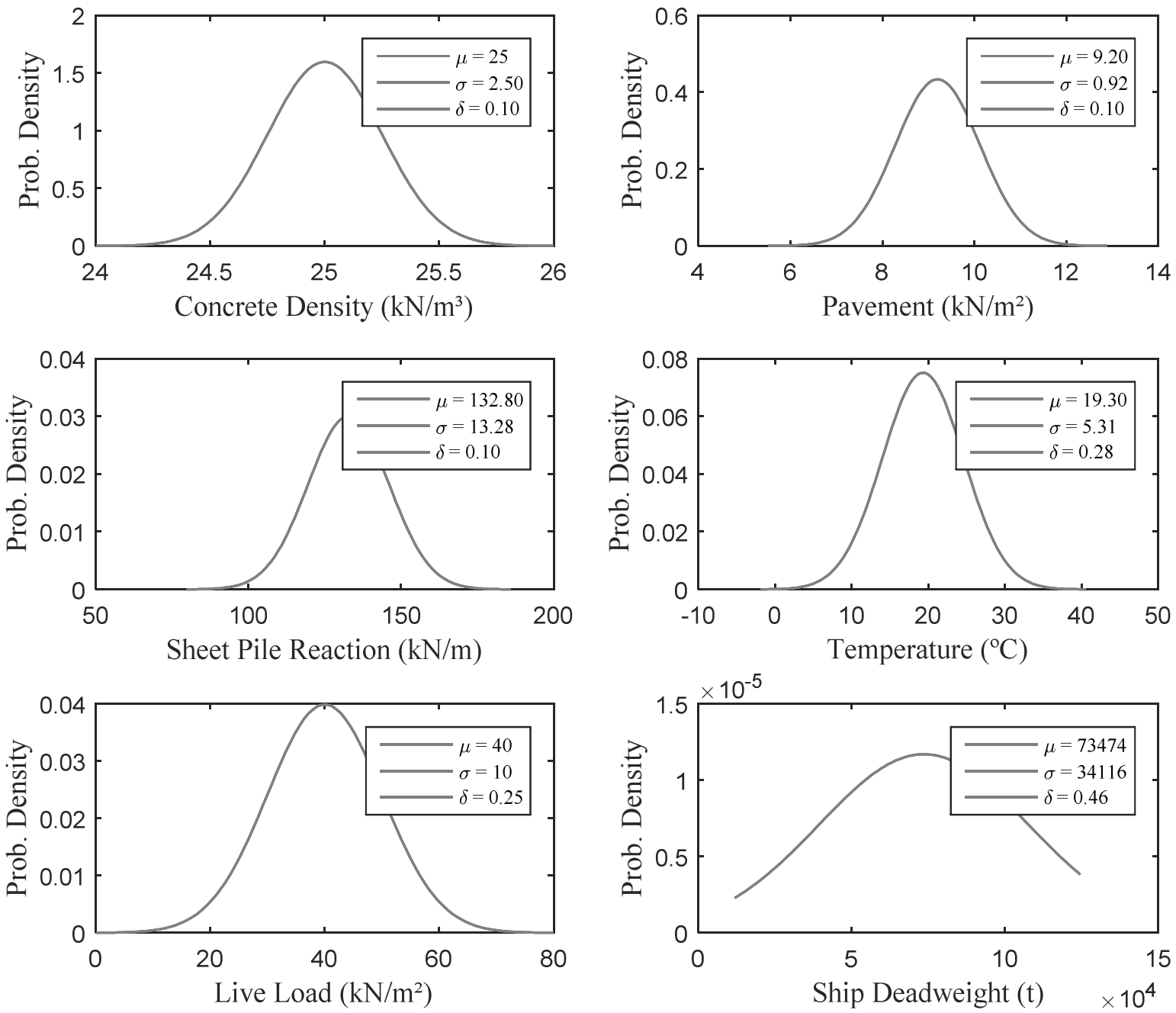

Figure 3: Input random parameters statistics and PDFs.

Statistical parameters for permanent actions are easily found in the probabilistic analysis or reliability theory bibliography, e.g. Nowak e Collins (2000), Harr (1987) and JCSS (2001). Following JCSS recommendation, to actions such as concrete and pavement self-weight (input by concrete density and pavement layer distributed weight) and the sheet pile horizontal reaction, coefficients of variation of 0.10 were assumed. The mean values of those actions were obtained from the TECON's wharf design report. Values of $40 \mathrm{kN} / \mathrm{m}^{2}$ are usually used to live loads in the design of container terminal berths (THORESEN, 2014), thus that was used as the mean for the live load, with 0.25 as the assumed coefficient of variation. To obtain the statistical parameters of temperature values the Brazilian National Institute of Meteorology (INMET) website was consulted. The institute offers openly on its website temperature daily measurements made over the years in several cities of Brazil. A series of measurements for Rio Grande city referring to 2011-2015 years was used. For ship berthing force evaluation, the random variable utilized was the ship deadweight. Data of ships berthed at TECON Rio Grande is available on company's website, and a ship deadweight series referring to the first semester of 2016 was obtained and fit to a normal probability function. For that random variable, it must be considered both minimum and maximum ship deadweight limits (assumed by minimum and maximum deadweight verified in the period), what can be done by using truncated normal distribution. 


\subsubsection{Load combinations}

A total of ten load combinations were analyzed in this work. Combinations 1.0 and 1.1 considered the structure without any equipment on it, but without and with live load respectively. In combinations 1.2 to

1.5, in addition to permanent, live and ship berthing loads it was considered the existence of one or two STS cranes in different positions. The STS cranes locations, concerning to combinations 1.2 to 1.5 respectively, were central (1.2), left (1.3), right (1.4) and both left and right (1.5). Similarly, but considering MHCs instead of STS cranes, in combinations 1.6 to 1.9 the MHCs were positioned at center (1.6), left (1.7), right (1.8), and both left and right (1.9). One important observation is that live loads must be excluded from analysis at the regions where MHCs are located, but not when STS cranes are on the structure, once these equipment allow traffic under themselves. As the piles are under water, temperature variations were input only on the superstructure frame. In all combinations the berthing force was introduced at left side fender. A schematic arrangement of combination 1.3 is shown in Fig. 4.

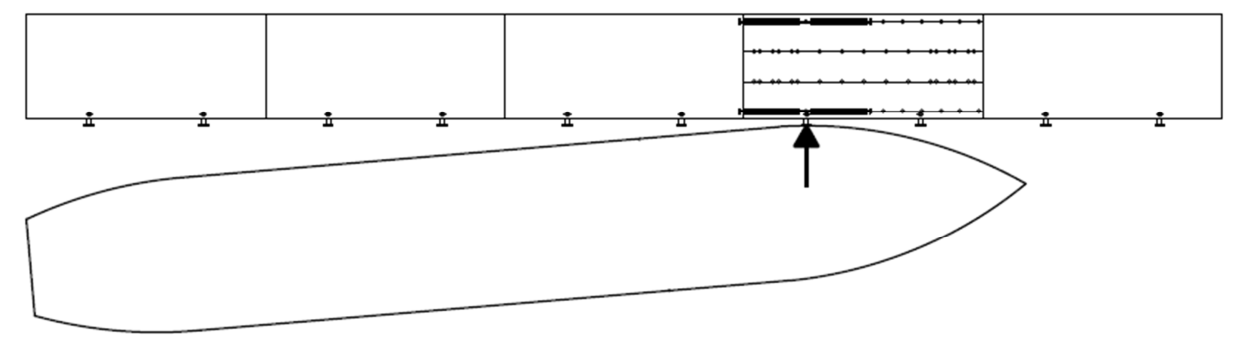

Figure 4: General arrangement of combination 1.3.

\subsubsection{Monte Carlo simulations}

Monte Carlo Simulations (MCS) is a numerical process of repeatedly calculating a mathematical or empirical operator in which the variables within the operator are random or contain uncertainty with prescribed probability functions (ANG e TANG, 2007). The values of the different input random parameters are sampled from the respective probability distributions in each repetition, and the results from each repetition may be considered as a sample of the random output variables. For the sampling of input random variables, several optimization techniques have been developed, and in this work the Latin Hypercube Sampling (LHS) method was used. Thus, input random parameters were the structural actions presented in Fig. 3, and output parameters were the minimum and maximum axial forces at the pile heads in each simulation. A total of 2000 simulations for each combination were performed, and a flowchart for the probabilistic analysis presented on this work is shown in Fig. 5. 


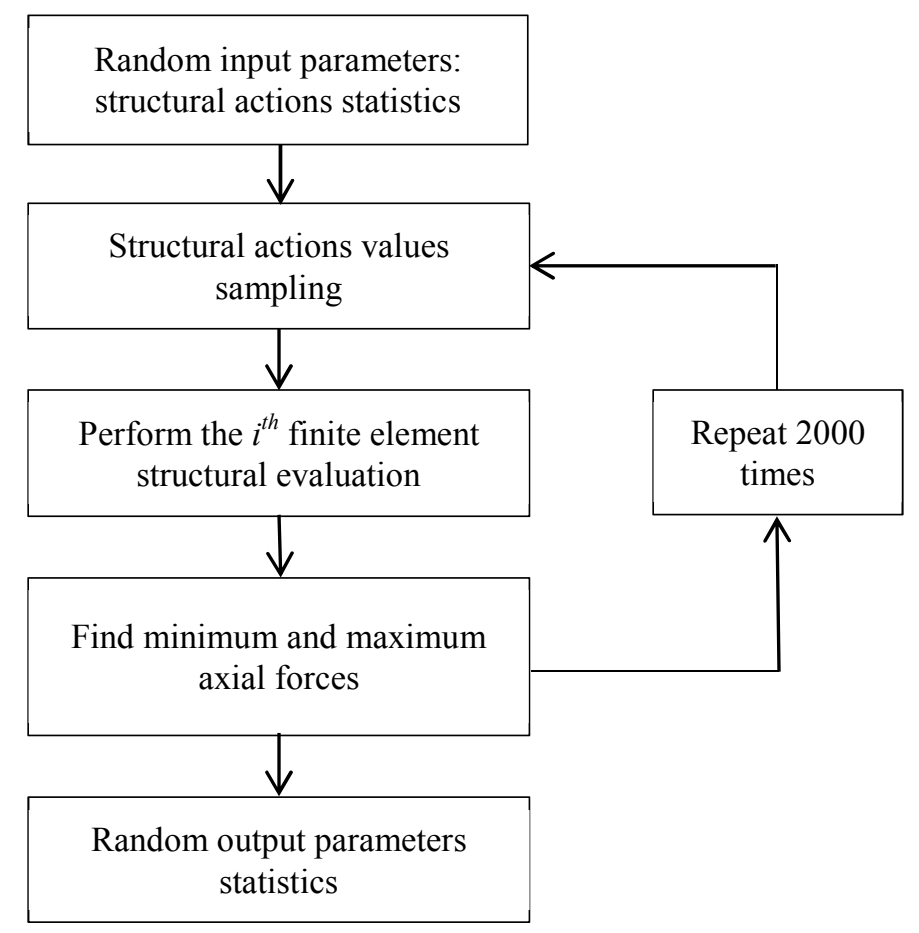

Figure 5: Flowchart of the performed structural probabilistic analysis.

\section{RESULTS AND DISCUSSION}

Table 1 shows the statistics of the output parameters obtained in the performed analyses. For the maximum compression forces, combination 1.2 led the structure to the maximum values, which occurred mostly at the piles under the STS crane rail located at the structure front. As the inclined piles (P14 to P19, P25 to P36 and P42 to P47, see Fig. 1) play the main roles in resisting to the horizontal loads, it was verified that the maximum tension forces occurred basically at those elements, and the combination 1.0 led the strcutcure to the maximum values. As also presented in Table 1, the parameters used for sorting the combinations in worst to better order was the absolute value of

Table 1: Statistics of the output parameters.

Comb.

\begin{tabular}{ccccccccc} 
& {$[\mathbf{k N}]$} & {$[\mathbf{k N}]$} & & {$[\mathbf{k N}]$} & {$[\mathbf{k N}]$} & {$[\mathbf{k N}]$} & & {$[\mathbf{k N}]$} \\
\hline 1.0 & -1463.2 & 130.0 & 0.09 & -1853.3 & 795.1 & 127.2 & 0.16 & $\underline{\mathbf{1 1 7 6 . 8}}$ \\
1.1 & -2128.3 & 216.0 & 0.10 & -2776.3 & 230.8 & 193.1 & 0.84 & 810.3 \\
1.2 & -2320.4 & 192.8 & 0.08 & $\underline{\mathbf{- 2 8 9 8 . 6}}$ & 239.5 & 193.1 & 0.81 & 819.0 \\
1.3 & -2241.9 & 192.7 & 0.09 & -2819.9 & 231.0 & 193.2 & 0.84 & 810.7 \\
1.4 & -2238.6 & 192.8 & 0.09 & -2817.1 & 192.1 & 193.1 & 1.01 & 771.4 \\
1.5 & -2292.1 & 192.2 & 0.08 & -2868.8 & 192.5 & 193.2 & 1.00 & 772.0 \\
1.6 & -2102.1 & 197.2 & 0.09 & -2693.6 & 217.3 & 197.3 & 0.91 & 809.1 \\
1.7 & -2133.5 & 223.4 & 0.10 & -2803.7 & 282.8 & 154.6 & 0.55 & 746.7 \\
1.8 & -1977.6 & 279.7 & 0.14 & -2816.8 & 581.5 & 123.7 & 0.21 & 952.5 \\
1.9 & -1555.7 & 110.9 & 0.07 & -1888.5 & 550.0 & 125.2 & 0.23 & 925.5 \\
\hline
\end{tabular}




\subsection{Minimum axial forces (maximum compressions)}

The probability distributions of the minimum axial forces (maximum compression) found on each simulation for all ten combinations are compared in Fig. 6. It has been observed that the minimum axial forces occured in combinations with live loads and STS cranes located in the center of the structure. That can be justified by some reasons, as the high equipment self-weight and by the impact force acting relieving the high compression state caused in some inclined piles by the horizontal sheet pile reaction at the rear beam, causing the maximum compression at the vertical piles appear in the structure front. Although the figure shows that the worst case were found in combination 1.2, it can be seen that the three worst PDFs resulted very similar. In that combination, the maximum compression forces occurred mainly at pile P53, which is a vertical one located in the center of the wharf front line of piles.

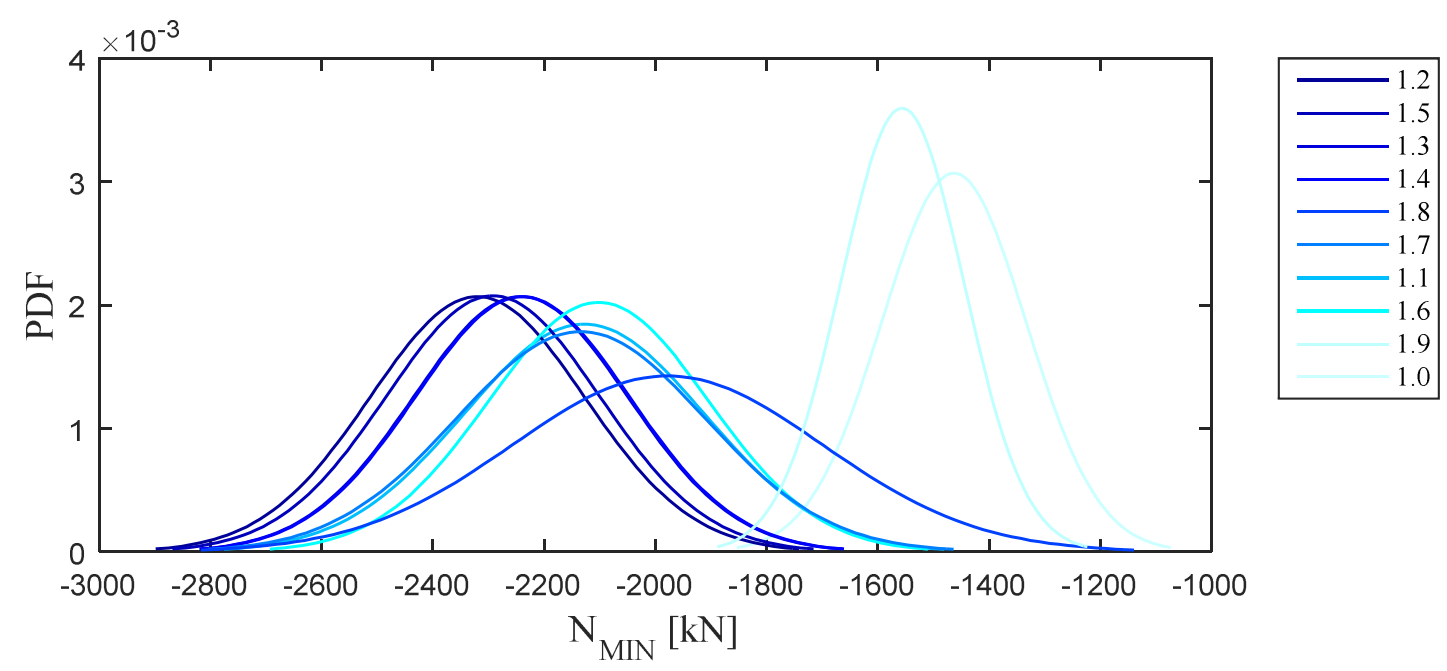

Figure 6: PDFs of $\mathrm{N}_{\mathrm{MIN}}$.

\subsection{Maximum axial forces (compression/tension)}

The probability distributions of the maximum axial forces in each simulation (minimum compression or maximum tension) for the ten combinations are compared in Fig. 7. It has been observed that maximum axial tension forces occur in the combination 1.0, which have no live loads or equipment acting in the structure. As the horizontal external loads grow in intensity, considerable tension forces can arise in some inclined piles. As shown in Fig. 7, combinations 8 and 9 also presented themselves as those that can bring high tension forces to the piles. For the combination 1.0, the maximum tension forces occurs basically in piles P29 and P46, which are inclined rearwards in order to resist horizontal forces. 


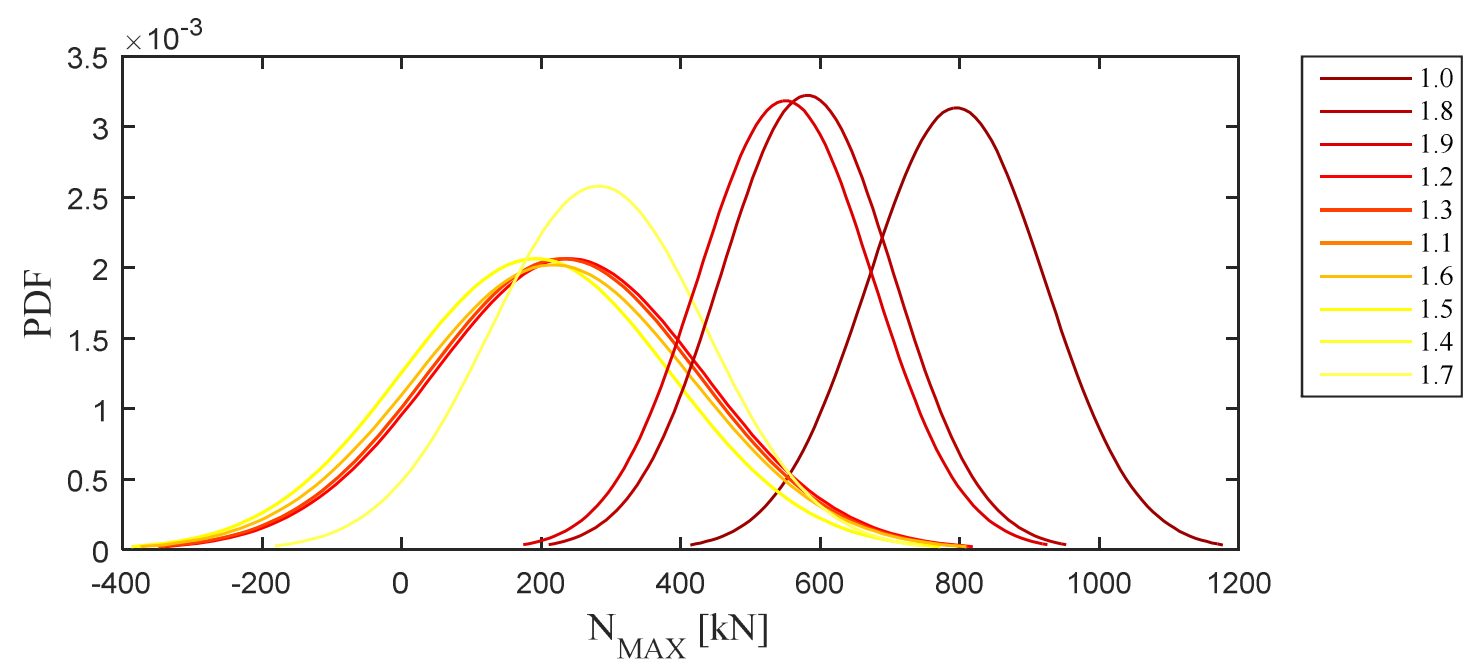

Figure 7: PDFs of $\mathrm{N}_{\mathrm{MAX}}$.

\subsection{Linear correlation coefficients between input and output parameters}

The correlation coefficients between the input and output parameters are very important to understand the structural behavior. Table 2 presents the linear correlation coefficients between the input and output parameters for the worst cases to compression (1.2) and tension (1.0) forces.

For the compression forces, the highest correlations were obtained with the live loads, followed by the concrete self-weight. The negative values for those linear coefficients are due to compression intensity grows towards negative values. For the tension forces, the highest correlations were obtained mainly for the landfill acting in the rear beam, as expected, and also followed by the concrete self-weight.

Table 2: Linear correlation coefficients between axial forces and structural actions.

\begin{tabular}{ccccccc}
\hline Comb. & & & & & & \\
\hline 1.2 & -0.24 & -0.06 & -0.02 & -0.02 & $\underline{-0.96}$ & 0.02 \\
1.0 & -0.18 & -0.07 & $\underline{0.95}$ & 0.02 & - & 0.04 \\
\hline
\end{tabular}

\section{CONCLUSIONS}

This work presented a probabilistic analysis of an existing container terminal wharf. Considering ten external load combinations, Monte Carlo Simulations were performed in a finite element structural model. The ANSYS Probabilistic Design System package was used for the simulations, and the finite element structural model was built in ANSYS APDL Mechanical package.

The applied methodology proved to be extremely capable to reach the proposed objectives, which consisted in obtaining the statistical parameters of the minimum and maximum axial forces at the structure pile heads. Therefore, ANSYS possibility to be programmed through its Parametric Design Language (APDL) showed itself as a powerful tool for probabilistic analysis of complex structural systems. 
A comparison between the probability density functions of the output parameters was presented, with the analyzed combinations sorted in a worst to better order. Tables with the statistic parameters and the linear correlation coefficients between the input and output parameters were presented. It was observed that the vertical piles are more subjected to the minimum forces, while the inclined piles are more subjected to maximum axial forces. Although the highest absolute axial forces found at the piles are compressive, it was shown that high tension forces can arise, and in three combinations all piles work only under tension forces.

Finally, it is suggested the application of the presented methodology in further analyses, e.g. the inclusion of different structural and probabilistic aspects, and the consideration of design and reliability analyses parameters among the outputs.

\section{ACKNOWLEDGEMENTS}

The authors André Pereira Ramos and João Paulo Silva Lima thank CAPES for the master scholarships, and the author Mauro de Vasconcellos Real thank CNPQ for productivity grant.

\section{REFERENCES}

Alfredini, P.; Arasaki, E., 2009. Obras e gestão de portos e costas: a técnica aliada ao enfoque logístico e ambiental. 2ed. São Paulo: Edgard Blucher.

Ang, A. H-S; Tang, W.H., 2007. Probability Concepts in Engineering. Emphasis on Appllications to Civil and Environmental Engineering. 2ed. New York: Wiley.

ANSYS, 2016. ANSYS v. 16 User's Manual. Houston: Swanson Analysis System Inc.

ABNT - Associação Brasileira de Normas Técnicas, 2014. NBR 6118: Projeto de estruturas de concreto Procedimento. Rio de Janeiro

British Standard Institute, 2000. BS 6349-1: Maritime structures - Part 1: Code of practice for general. London.

British Standard Institute, 2004. BS 6349-4: Maritime structures - Part 4: Part 4: Code of practice for design of fendering and mooring systems. London.

Harr, M. E., 1987. Reliability-based design in civil engineering. McGraw-Hill, New York.

Haldar, A., 2006. Recent developments in reliability-based civil engineering. Singapore: World Scientific Publishing Co. Pte. Ltd.

JCSS - Joint Committee on Structural Safety, 2001. Probabilistic Model Code.

Liebherr, 2016. Technical Description Ship to Shore Gantry Cranes. $<$ http://www.liebherr.com/>.

Martha, L. F., 2010. Análise de estruturas: conceitos e métodos básicos. Rio de Janeiro: Editora Elsevier.

Mason, J., 1981. Obras Portuárias. Rio de Janeiro: Campus.

Nowak, A. S., Collins, K.R., 2000. Reliability of structures. USA: The McGraw-Hill Companies.

PIANC - World Association for Waterborne Transport Infrastructure, 2002. Guidelines for the Design of Fenders.

TECON - Terminal de Contêineres do Porto do Rio Grande. Projeto estrutural do cais do TECON Rio Grande.

Terex, 2010. Mobile Harbour Crane Catalogue. $<$ http://www.terexcranes.com>.

Persp. Online: exatas \& eng., Campos dos Goytacazes, 20 (08) 78-88 - 2018

seer.perspectivasonline.com.br 
Thoresen, C. A., 2014. Port's Design Handbook. 3ed. London: ICE Publishing.

Tsinker, G., 1997. Handbook of Port and Harbor Engineering: geotechnical and structural aspects. New York : Chapman \& Hall.

Tsinker, G., 2004. Port Engineering: Planning, construction, maintenance and security. New Jersey: John Wiley \& Sons.

Zienkiewicz, O. C., Taylor, R.L., 2000. The finite element method - Volume 1: The basis. 5ed. Oxford: Butterworth-Heinemann 